\title{
Supporting Information for cis-to-trans Isomerization Promoted by Pyridine as a Crucial Step for the Selective Preparation of trans- $\operatorname{Pt}(\mathrm{SAr})(\mathrm{Cl})\left(\mathrm{PAr}_{3}\right)_{2}$
}

\begin{abstract}
Fumikazu Yamashita, Hitoshi Kuniyasu, ${ }^{*}$ Jun Terao and Nobuaki Kambe*
Department of Molecular Chemistry \& Frontier Research Center, Graduate School of Engineering, Osaka University, Suita, Osaka 565-0871, Japan
\end{abstract}

Contents of Supporting Information. ${ }^{1} \mathrm{H}$ and ${ }^{31} \mathrm{P}$ NMR spectrum of trans-1e (pS2, S3), trans-1i (pS4, S5) and trans-11 (pS6, S7). The ${ }^{31} \mathrm{P}$ NMR spectra of crude reaction mixtures of run 5 in Table 4, run 7 in Table 4, and run 2 in Table 5 were shown in the following S8-S10. The peak at $\delta 23.1$ in S8 was assigned as trans-Pt( $\left(\mathrm{SC}_{6} \mathrm{H}_{4}-2-\mathrm{Cl}\right)_{2}\left(\mathrm{PPh}_{3}\right)_{2}$. The ratio of trans-1f/trans-4f was $98 / 2$. The peaks at $\delta 15.7$ and $\delta 22.5$ in S9 were assigned as cis- $\mathrm{PtCl}_{2}\left(\mathrm{PPh}_{3}\right)_{2}$ and trans-Pt( $\left(\mathrm{SC}_{6} \mathrm{H}_{4}-2-\mathrm{Cl}\right)_{2}\left(\mathrm{PPh}_{3}\right)_{2}$, respectively. The ratio of trans-1h/cis-2a/trans-4h was 92/4/4. The peaks at $\delta 12.7$ and $\delta 20.8$ in S10 were assigned as cis- $\mathrm{PtCl}_{2}\left[\mathrm{P}\left(\mathrm{C}_{6} \mathrm{H}_{4}-4-\mathrm{OMe}\right)_{3}\right]_{2}$ and trans- $\mathrm{Pt}\left(\mathrm{SC}_{6} \mathrm{H}_{4}-4-\mathrm{Me}\right)_{2}\left[\mathrm{P}\left(\mathrm{C}_{6} \mathrm{H}_{4}-4-\mathrm{OMe}\right)_{3}\right]_{2}$, respectively. The ratio of trans-11/cis-2c/trans-4l was 87/4/9. 


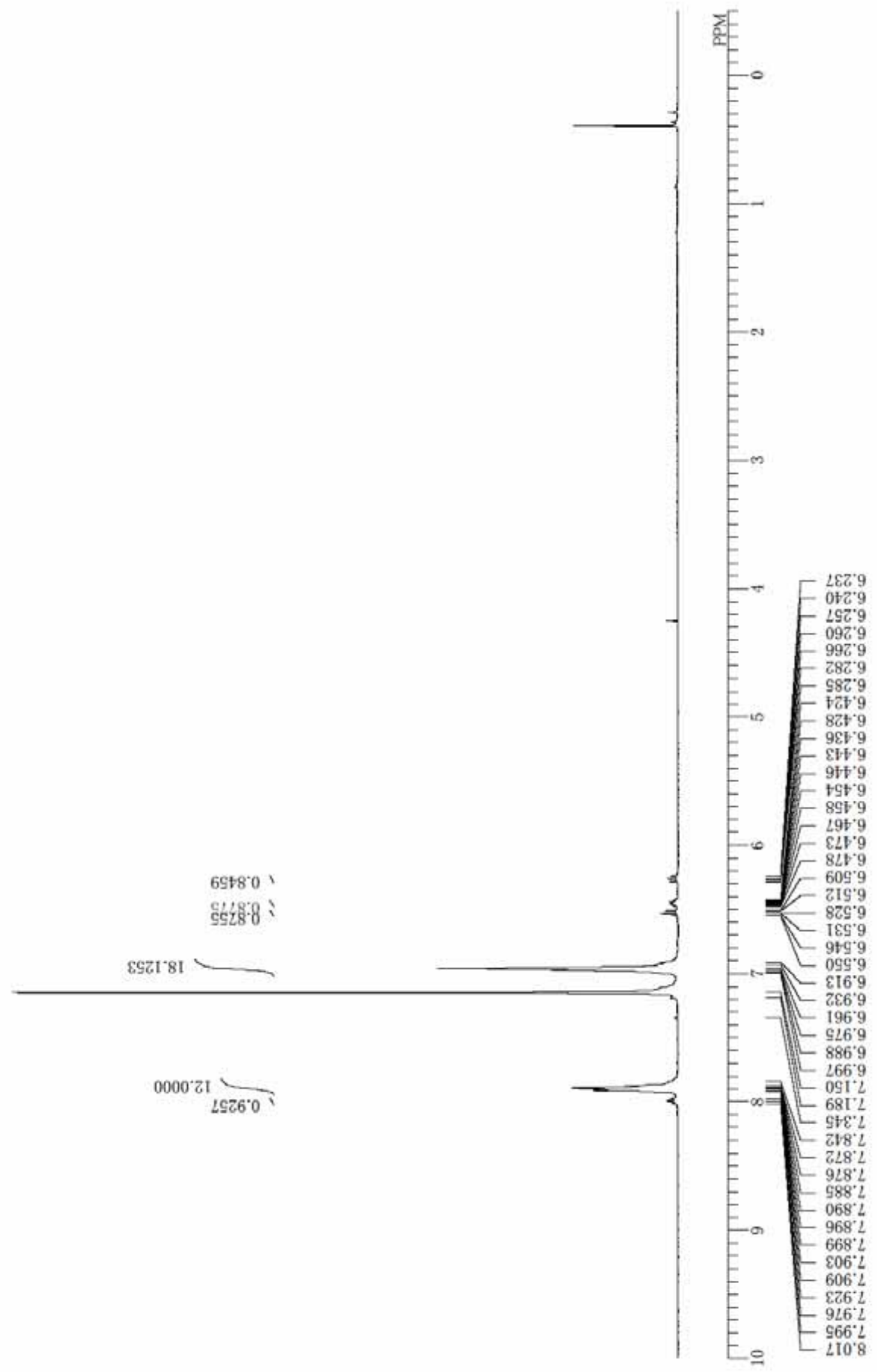




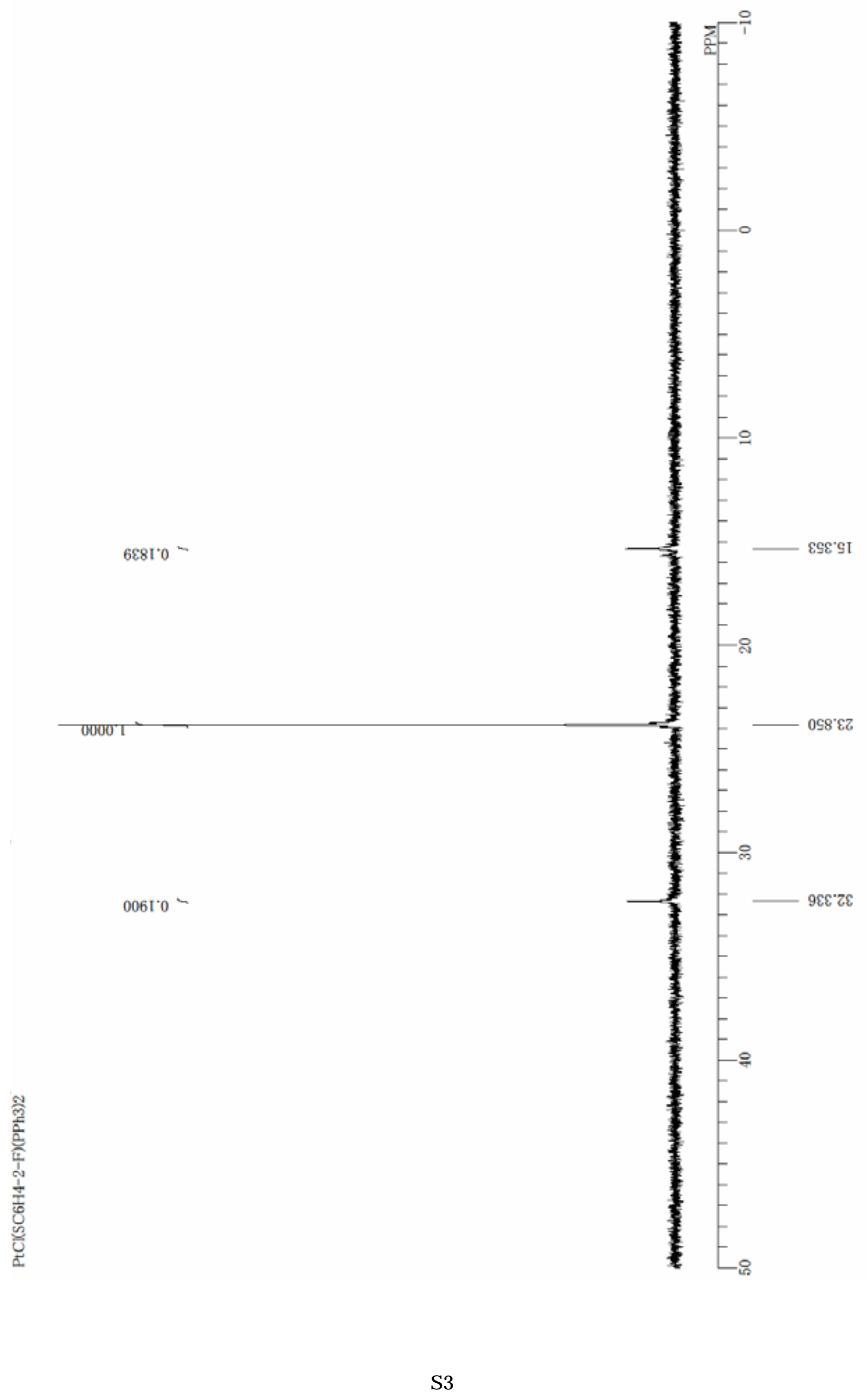




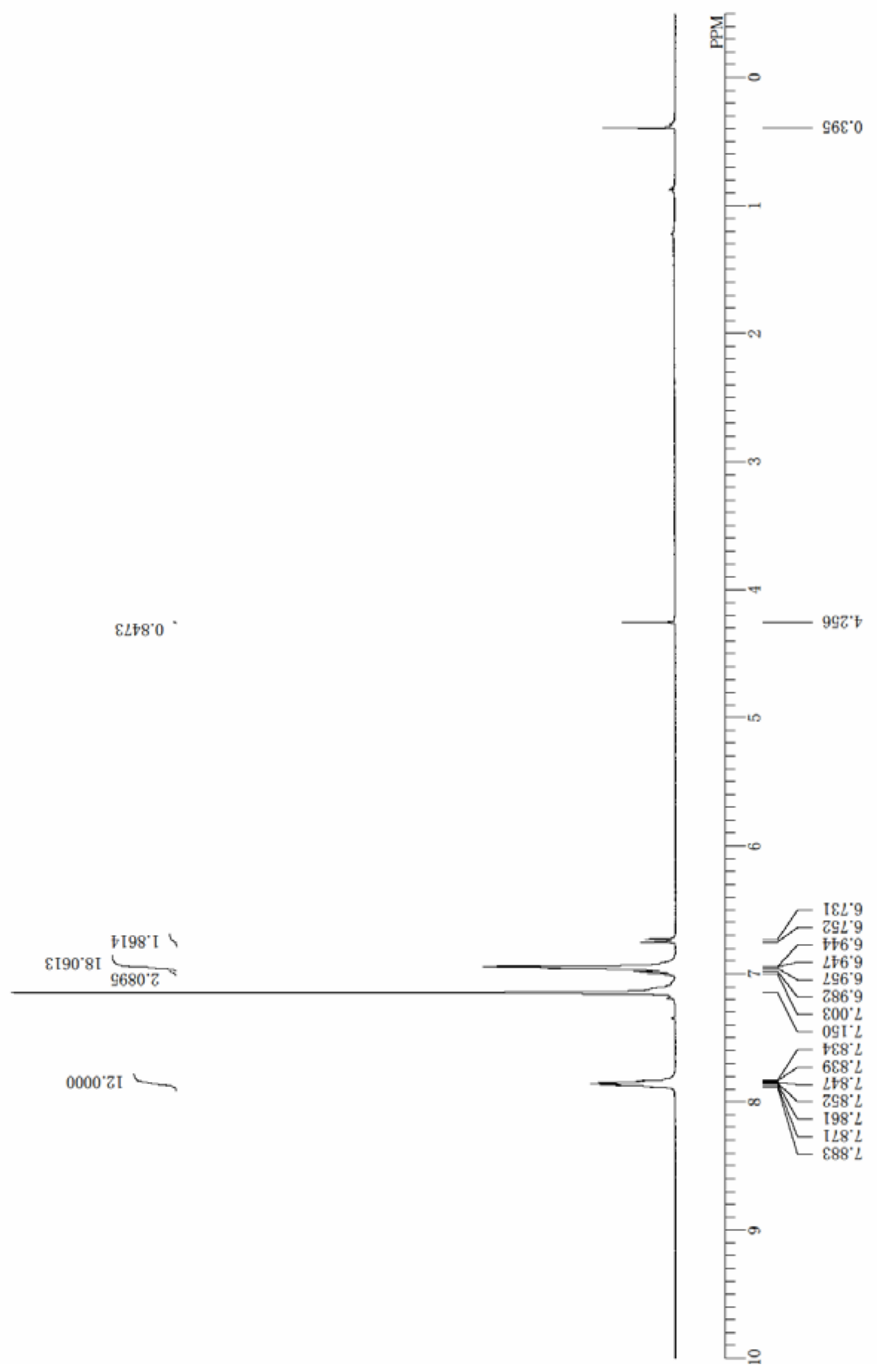




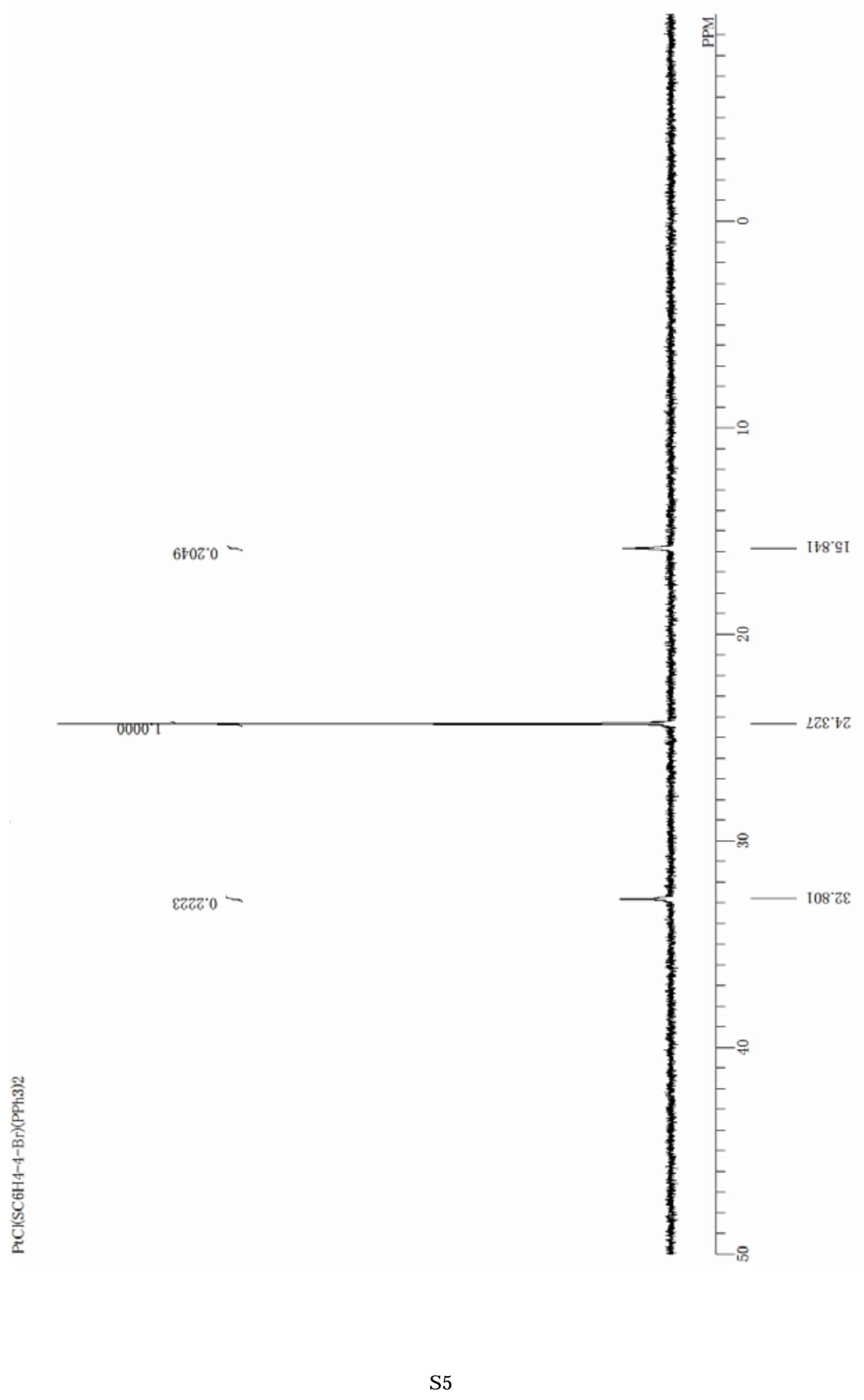




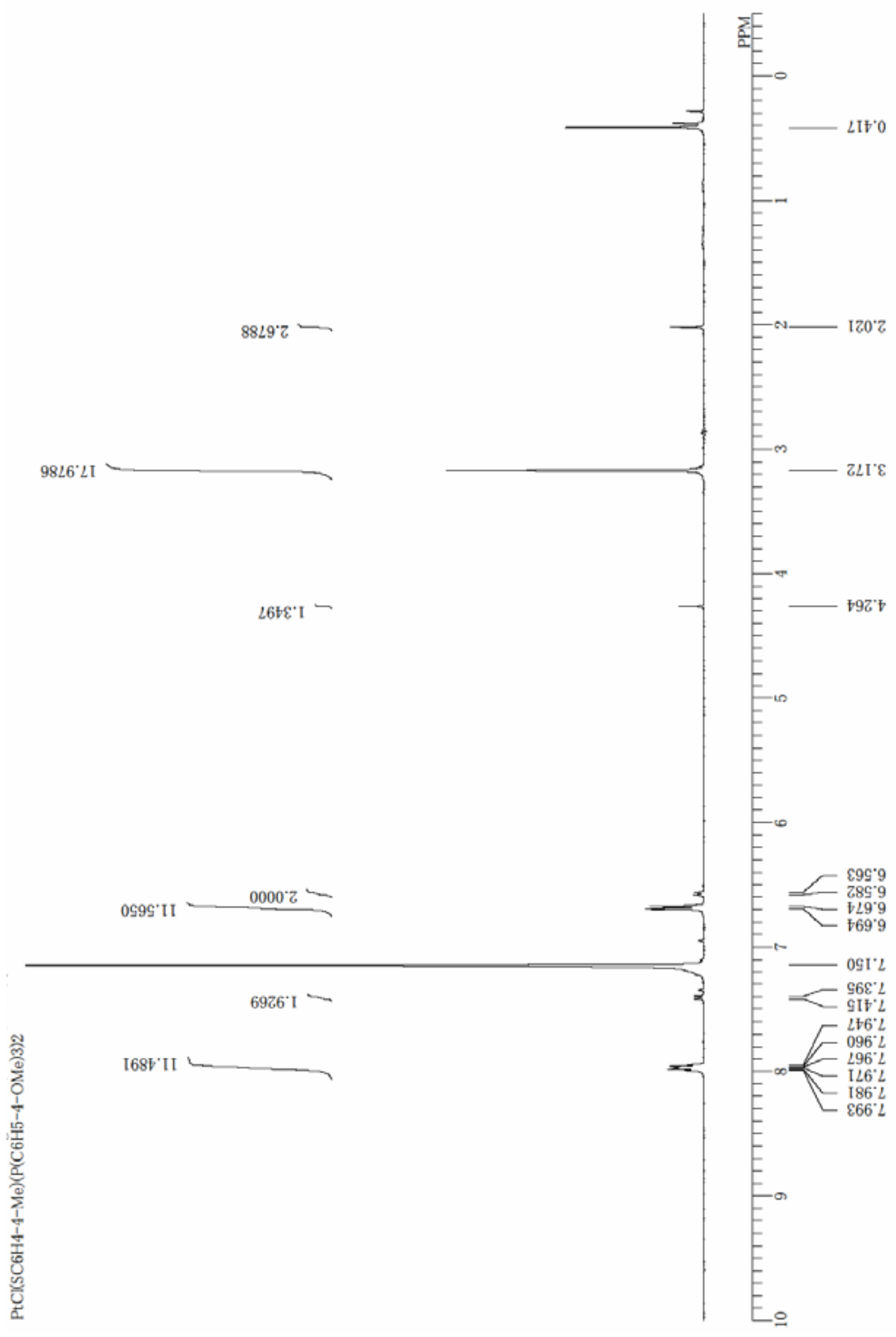




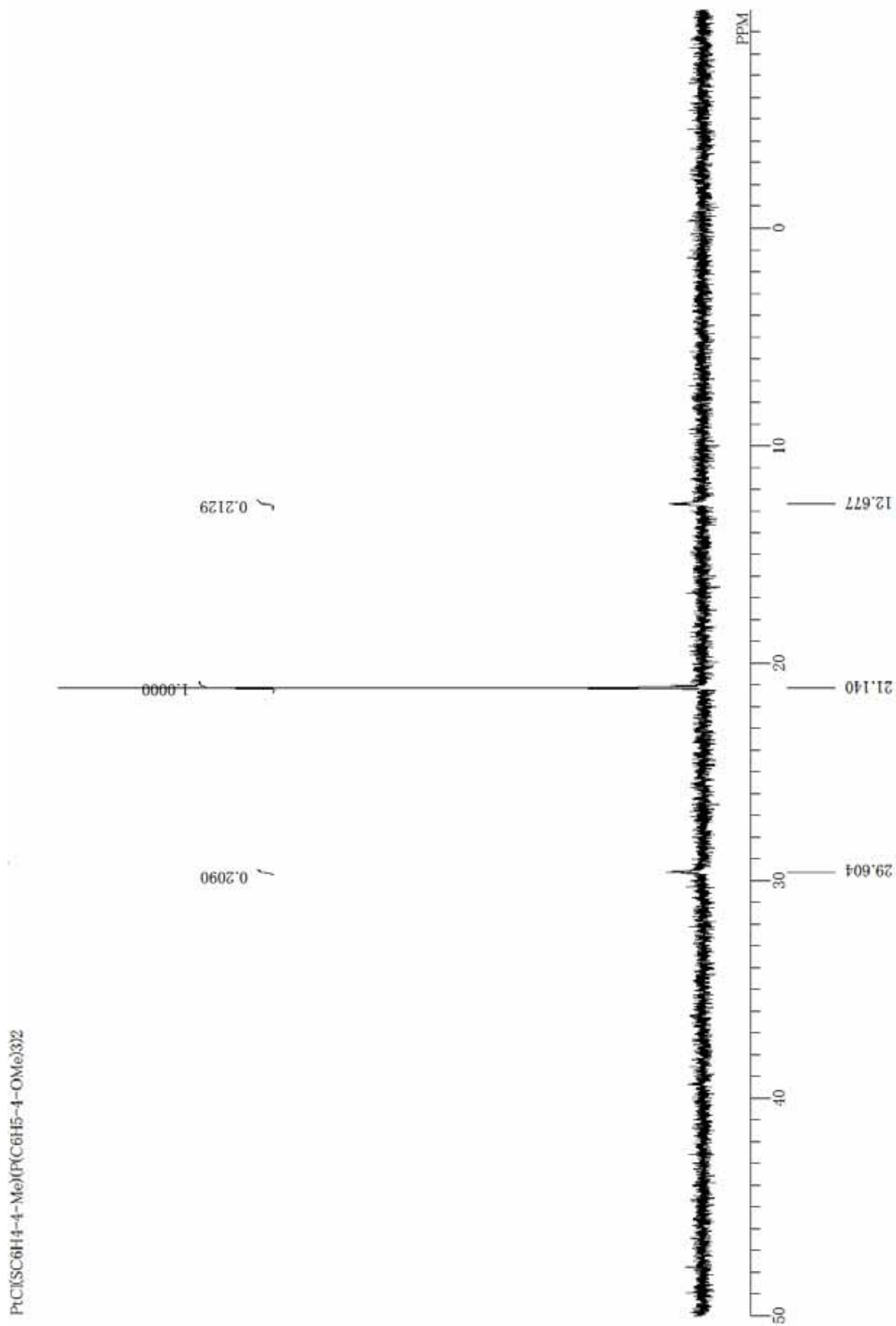




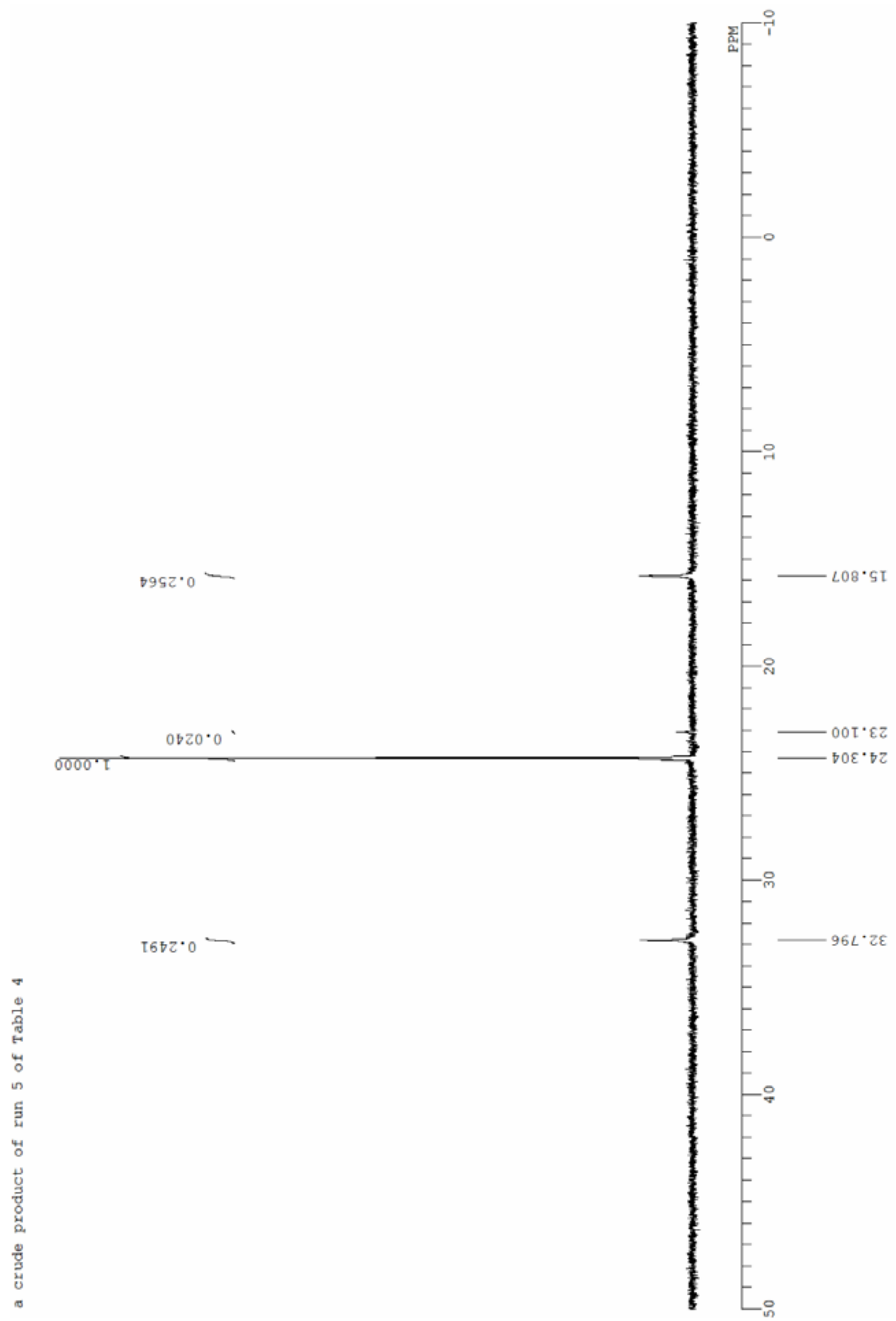

S8 


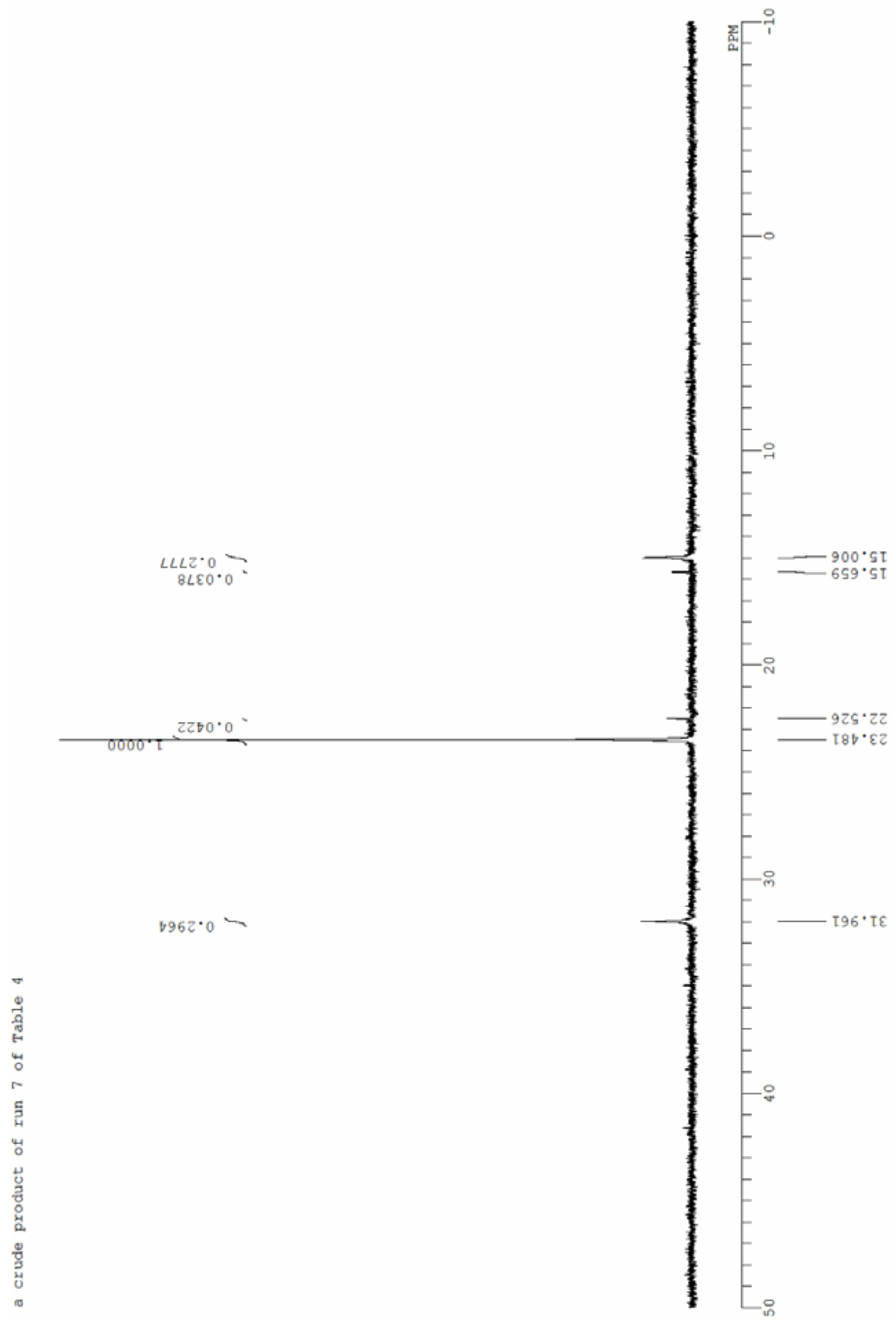

S9 


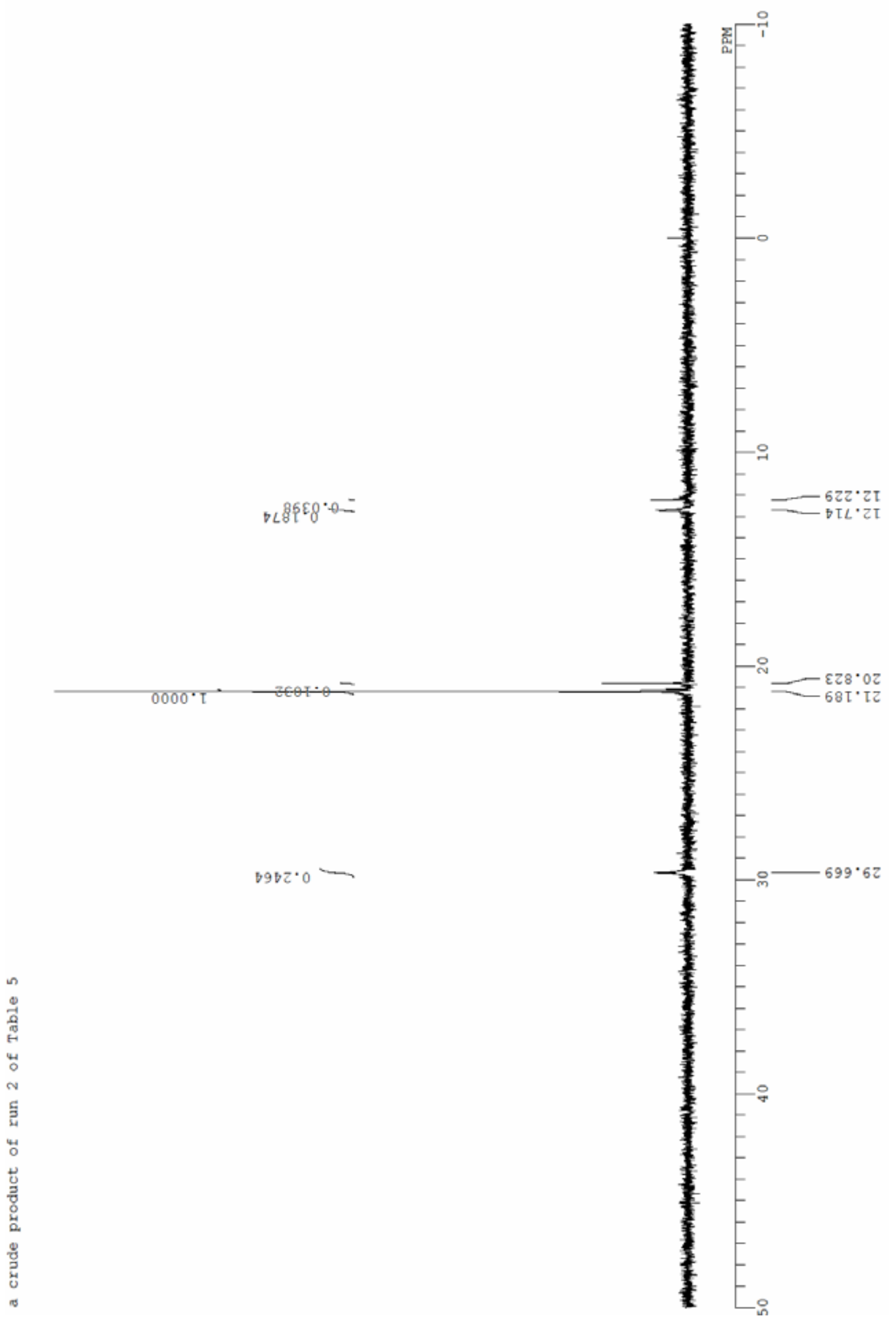

